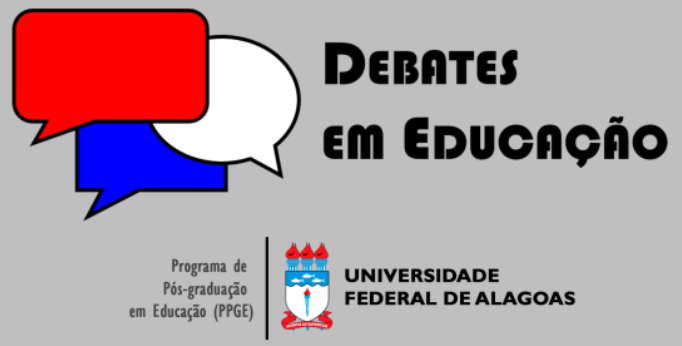

ISSN Eletrônico 2175-6600

Vol. 12 | Número Especial | 2020

Greice Ferreira da Silva

(9) iD

Universidade Estadual de Londrina (UEL)

grebalet@terra.com.br

Cyntia Graziella Guizelim Simões

Girotto

(9) iD

Universidade Estadual Paulista (UNESP)

cyntiaunespmarilia@gmail.com

Ângela Maria Franco Martins Coelho de

Paiva Balça

(9) iD

Universidade de Évora (UE)

apb@uevora.pt

\section{LEITURA E LEITORES NA EDUCAÇÃO INFANTIL: AS HISTÓRIAS EM QUADRINHOS E A APROPRIAÇÃO DO ATO DE LER}

\section{RESUMO}

Objetivo deste artigo é abordar alguns importantes aspectos sobre o ensino do ato de ler na escola e suas implicações para a formação da criança leitora, compreendendo o ato de ler como um ato cultural e historicamente constituído. Este artigo faz parte de uma investigação maior que busca discutir a inserção da criança no mundo da cultura escrita. Neste recorte será enfatizado os dados especificamente sobre a situação de leitura do gênero discursivo histórias em quadrinhos na Educação Infantil com crianças de 5 e 6 anos. Os apontamentos argumentativos apresentados se fundamentam no arcabouço teórico científico da escola de Vygotsky, na perspectiva do Círculo de Bakhtin e de estudiosos da leitura e das histórias em quadrinhos. Aponta-se como resultados que o ensino e a aprendizagem da leitura são movidos pela necessidade e pelo interesse das crianças e estão intimamente relacionados com a produção de sentido num processo interativo.

Palavras-chave: Educação Infantil. Cultura Escrita. Formação da criança leitora. Ato de ler. Histórias em quadrinhos.

\section{READING AND READERS IN CHILDHOOD EDUCATION: THE STORIES IN COMICS AND THE APPROPRIATION OF THE ACT OF READING}

\begin{abstract}
The purpose of this article is to address some important aspects about teaching the act of reading at school and its implications for the education of the child reader, understanding the act of reading as a culturally and historically constituted act. This article is part of a larger investigation that seeks to discuss the child's insertion in the world of written culture. In this section, the data will be emphasized specifically on the reading situation of the discourse genre comic books in Early Childhood Education with children aged 5 and 6 years. The argumentative notes presented are based on the scientific theoretical framework of the Vygotsky school, from the perspective of the Bakhtin Circle and scholars of reading and comics. The results point out that teaching and learning to read are driven by the need and interest of children and are closely related to the production of meaning in an interactive process.
\end{abstract}

Keywords: Early Childhood Education. Written Culture. Training of the reading child. Act of reading. Comics.

Submetido em: 02/04/2020

Aceito em: 20/07/2020

Publicado em: 10/12/2020

d. http://dx.doi.org// 0.28998/2 |75-6600.2020v I 2nEspp | | 6- | 3 | 


\section{INTRODUÇÃO}

A criança e a infância tem sido alvo de muitas pesquisas em diferentes áreas do conhecimento (ARIÈS, 1978; LEONTIEV, 1988; MELLO, 2007; SARMENTO; PINTO, 1997; VYGOTSKI¹, I 995; entre outros). Este artigo, recorte de uma pesquisa maior, elege como tema o processo de inserção da criança pequena na cultura escrita, a sua formação leitora e o uso dos gêneros discursivos na Educação Infantil, particularmente, o uso das histórias em quadrinhos, uma vez que objetiva pensar em práticas de leitura nesse momento da escolaridade de modo que a criança estabeleça relações com o escrito, interaja com ele e pense nos diferentes modos de usá-lo. Objetiva também apresentar situações de leitura em que as crianças, não sendo ainda convencionalmente alfabetizadas, mas em processo inicial de aprendizagem do ato de ler, pensem sobre a língua e sobre o seu funcionamento de forma dialógica e dinâmica.

Ao tratarmos sobre a formação leitora desde a Educação infantil, nos propomos a entender como a criança desde pequena pode pensar e estabelecer relações com a escrita descartando efetivamente a ideia de alfabetizá-las precocemente, uma vez que a aceleração da escolarização (ZAPHORÓZETS, I987; MELLO, 1999) e a preocupação em alfabetizar as crianças na Educação Infantil - com ênfase no domínio do código linguístico, sem fazer o uso social da leitura e da escrita para o cotidiano -, faz perpetuar uma educação tecnicista (BRITO, 2005), abrevia a infância e influencia todo o desenvolvimento da inteligência e da personalidade da criança (MUKHINA, 1996; MELLO, 1999).

Para tanto o presente texto está dividido em mais quatro tópicos: Pesquisando com crianças - o processo investigativo em foco; Apropriação da linguagem escrita e o ensino do ato de ler na pequena infância; Situação de leitura de histórias em quadrinhos na educação infantil: significado/sentido na leitura; Palavras finais; finalizando com as Referências utilizadas.

\section{PESQUISANDO COM CRIANÇAS: O PROCESSO INVESTIGATIVO EM FOCO}

A atitude adotada na pesquisa com as crianças e, aqui apresentada, é a tentativa de ir além das aparências do fenômeno para aproximar-se da sua essência (KOSIK, 1976), dado que essência e aparência são produzidas pelo mesmo complexo social (MARX, 1974). Assim, nos propusemos a pensar as crianças

\footnotetext{
' Nas diversas obras do autor russo e naquelas que têm seus pressupostos como objeto, a grafia de seu nome aparece de maneira diferenciada: Vigotskii, Vigotski, Vygotsky, Vygotski. Optamos, neste trabalho, pela grafia Vygotsky. Entretanto, para ser fiel às indicações presentes nas referências bibliográficas das quais utilizamos, no caso de citações diretas ou indiretas, manteremos a grafia presente nos originais.
} 
não como sujeitos passivos, mas, ao contrário, procura entender a criança como sujeito ativo em todo o processo de elaboração, reflexão, análise e de possíveis transformações.

Nesse contexto, um processo investigativo centrado nas crianças, deve pretender conhecer as crianças como únicas, bem como suas formas específicas de se relacionar com o mundo dos instrumentos culturais objetivos - materiais - como a leitura, a escrita, o uso dos objetos humanos, ou subjetivos imateriais - como as relações, as interações, as conceitualizações e os parceiros mais experientes. Isto posto, revela uma possibilidade de descartar práticas de pesquisa colonizadoras e adultocêntricas em que são evidenciadas as disparidades de poder entre adultos e crianças e se considera a alteridade da infância e os diferentes aspectos que a distinguem do outro - adulto.

Martins Filho e Barbosa (s.d., p. 3) esclarecem que ao contextualizar historicamente as teorias de metodologias de pesquisas com crianças, percebe-se que elas nunca foram consultadas, olhadas, ouvidas e muito menos consideradas. Segundo Qvortrup (1999), as crianças nunca foram estudadas por seu próprio mérito na história da humanidade. Para a ciência teria que prevalecer a racionalidade adultocêntrica, a qual descarta de certa forma, as manifestações das crianças. Nesse contexto, o que seria indicado pelas crianças não teria cientificidade. "Se hoje podemos criticar as metodologias tradicionais de pesquisas com/sobre crianças, muito ainda temos que construir e avançar para garantir a cientificidade do protagonismo infantil" (MARTINS FILHO; BARBOSA, s.d., p. 3).

Problematizar a dimensão do ensino e da aprendizagem do ato de ler no tempo da infância da criança pequena requer assumir um dado conceito de criança e de infância. Isso exige pensar na criança concreta - historicamente situada -, "com sua própria biografia, carregada de significados e sentidos próprios do tempo e do espaço em que vive, das relações que trava, das expectativas a que é submetida" (BISSOLI, 2005, p. $60-61$ ).

A criança é um sujeito social e por tal razão, na pesquisa, a relação entre adulto e criança não pode ser uma relação de submissão, mas de mediação, interação e negociação. Para negociar é preciso construir formas de comunicação e participação com, para e das crianças (MARTINS FILHO; BARBOSA, s.d., p. 5).

Enfim, essas proposições se direcionam para a necessidade de se buscar na pesquisa com as crianças um processo dialógico, tal como procuramos realizar. $\bigcirc$ ser humano, a criança, deve entrar em contato com os fenômenos do mundo circundante por meio de outros homens, ou seja, num processo de comunicação com eles. Pela sua função, esse processo é, portanto, um processo de educação e produção cultural (VYGOTSKI, 1995). Ao assumirmos essa posição, pretendemos ter rompido nesse trabalho de investigação com a ideia de infância como objeto de constante regulação e controle, sendo necessário, por isso, conhecer as especificidades dessa etapa da vida. Desta forma, perceber as crianças nas relações que elas travam com o professor, com o conhecimento e com elas mesmas é o que orientou 
todo o processo da pesquisa, ora apresentada em apenas um dos seus recortes: as situações de leitura com crianças utilizando as histórias em quadrinhos.

A história em quadrinhos já foi considerada erroneamente uma subliteratura infantil, nociva para quem a lê ou apenas um entretenimento descompromissado de crianças e jovens. As razões se encontram em sua própria história, em argumentos infundados sobre a influência dos quadrinhos na delinquência juvenil ou como promotora do desinteresse das crianças e jovens pela leitura de livros formais, tradicionais.

$\mathrm{Na}$ Educação Infantil como as crianças podem se apropriar da leitura das histórias em quadrinhos? Quais relações elas podem estabelecer com esse gênero discursivo? Baseado na integração da linguagem escrita e a linguagem visual nas histórias em quadrinhos, algumas respostas podem ser obtidas. Moya (1993, p. 150) afirma que:

A seriação de quadrinhos, que se assemelha a uma lenta projeção cinematográfica - ou a cenas fixas, de uma singela peça de teatro -, pode considerar-se, na medida solicitada pela mente infantil, adequada ilustração do texto; na realidade, assume o caráter de verdadeiro relato visual ou imagístico, que sugestivamente se integra com rápidas conotações do texto escrito, numa perfeita identificação e entrosamento das duas formas de linguagem: a palavra e o desenho. Exatamente como convém ao caráter sincrético e intuitivo do pensamento infantil.

Pode-se dizer que a ação narrativa das histórias em quadrinhos é agradável e satisfaz a criança porque, ao contrário das leituras escolares, provoca um comportamento ativo, vigilante, em que o imaginário e o lúdico estão sempre presentes. As histórias em quadrinhos são atrativas para a criança porque correspondem às suas necessidades e interesses, nos quais também se incluem os jogos e as brincadeiras.

O recorte apresentado faz parte de uma investigação maior desenvolvida numa escola pública municipal de Educação Infantil de uma cidade do interior do estado de São Paulo em que participaram a professora e 2 I crianças de uma turma. Trata-se de uma pesquisa-ação e priorizou-se a relação dialógica entre pesquisador e pesquisados. Os procedimentos metodológicos envolveram entrevistas semiestruturadas com as crianças da pesquisa e observações com o objetivo de coletar dados sobre a situação inicial dos sujeitos antes da interferência da pesquisa-ação, para no final do projeto ser possível comparar dados iniciais e finais. Por meio dos dados coletados inicialmente foram elaboradas situações de leitura que favorecessem a interação das crianças com as histórias em quadrinhos e essas leituras foram mediadas pela professora. Foram desenvolvidas situações de leitura para evidenciar a atribuição de sentido de modo que pudessem provocar nas crianças a necessidade de novas leituras. Por se tratar de um recorte de uma pesquisa maior, enfatizamos nessa discussão a análise baseada na perspectiva enunciativa discursiva de Bakhtin de uma das situações de leitura proposta com tiras de HQ. 


\section{APROPRIAÇÂO DA LEITURA E O ENSINO DO ATO DE LER NA PEQUENA INFÂNCIA}

A concepção de linguagem interfere nos processos de ensino e de aprendizagem da leitura - na escolha dos materiais e nas estratégias de ensino (ARENA, 1992) - e por tal razão é necessário buscar coerência entre a concepção de linguagem e os procedimentos assumidos pelo professor uma vez que essas questões refletem diretamente nas relações estabelecidas nesse processo.

Para Bakhtin, a linguagem é essencialmente dialógica, o que pressupõe o outro, a atitude responsiva. Nessa perspectiva, a linguagem é vista como um "fenômeno de interação verbal" (BAKHTIN, 1992, p. 123) que se dá nas trocas ativas e dinâmicas entre os sujeitos que são produtores de enunciados. Desse modo, para que as crianças possam se apropriar da leitura, elas devem ser colocadas no fluxo desse processo que deve ser dialógico.

Partimos do pressuposto de que a linguagem escrita precisa ser apresentada desde o início à criança como um instrumento que tem como função social comunicar informações, ideias, sentimentos. Por isso, nos respaldamos em Vygotski, para o qual

\footnotetext{
Nós não negamos que seja possível ensinar a ler e a escrever as crianças de idade pré-escolar, inclusive consideramos conveniente que a criança saiba já ler e escrever ao ingressar na escola. Mas o ensino deve organizar-se de forma que a leitura e a escrita sejam necessárias de algum modo para a criança. (...) a escrita deve ter sentido para a criança, deve ser provocada por necessidade natural, como uma tarefa vital que é imprescindível. Unicamente então estaremos seguros de que a escrita se desenvolverá na criança não como um hábito de mãos e dedos, mas como um tipo realmente novo e complexo de linguagem. (VYGOSTKI, 1995, p. 20I, tradução nossa)
}

Em pesquisa outra realizada, Silva (2013) concluiu que professoras dão indícios de aceitarem o ensino de letras - identificação e junção -, sílabas e palavras, de forma natural, espontânea com o qual a criança "vai despertando", "deslanchando com a maturidade", o que acaba por descartar a intencionalidade do ensino, a mediação do professor e a compreensão de que dominar a escrita significa "uma transformação crítica em todo o desenvolvimento cultural da criança" (VYGOTSKI, I995, p. I84, tradução nossa).

Para a pesquisadora, as professoras participantes da pesquisa, consideram - e isso, na aparência, parece ser um avanço - que não adianta decodificar e que a criança precisa ler e entender o que lê. Acrescenta ainda que consideram que a criança decodifica letra por letra de uma palavra, mas que às vezes não presta atenção ao que lê e que o mesmo acontece com a escrita. Diante dessas afirmações, muito comum e recorrente em diversos outros discursos nas escolas de nossos diferentes 'brasis', emergem duas situações que merecem serem ressalvadas. A primeira se relaciona ao fato de que ler e entender parecem duas etapas distintas do ato de ler, o que não condiz com a concepção de leitura que entende a 
leitura como compreensão, como produção de sentido e como prática social, histórica e cultural (ARENA, 1992; CHARMEAUX, 1997; JOLIBERT, 1994).

Arena (2010) esclarece que ler

é a ação de atribuir sentido por meio de sinais gráficos, em situações elaboradas pela cultura humana. Essas atitudes constituintes do entorno, são vitais para a formação do leitor e são desenvolvidas nas relações com os gêneros enunciativos porque são as relações culturais que orientam os modos de ler. É importante entender que ensinar o sistema linguístico não é ensinar a ler; ensinar a ler é ensinar as próprias práticas sociais e culturais que exigem o domínio desse sistema. (ARENA, 2010, p. 242).

Nessa perspectiva, ler é uma forma de apropriar-se da cultura humana e seu ensino ultrapassa a mera decodificação de sinais gráficos e a vocalização, e se relaciona às formas de desenvolvimento do pensamento. Ao ensinar a ler, a atitude seria de ensinar a própria língua não somente como um instrumento de comunicação, mas como um instrumento do pensamento (ARENA, 20I0; FOUCAMBERT, I994; VYGOTSKY, 2000).

Segundo Arena (2010, p. 242-243),

Aprender a ler é necessário para a transformação contínua, progressiva, para um modo cada vez mais abstrato e profundo de pensar, que somente a relação com essa tecnologia chamada escrita pode proporcionar ao homem. Vista do ângulo da antropologia, a escrita apropriada pelo leitor revela-se como um poderosíssimo instrumento de desenvolvimento da mente humana, das funções psíquicas superiores, constituintes do progressivo processo de humanização de acordo com o pensamento de Vygotsky (2000).

Arena (20 I0) assevera, ainda, que é uma expressão comum nos planos escolares que diagnostica os alunos como incapazes de ler, de compreender e de interpretar. Este fato revela, em sua gênese, uma visão do ato de ensinar a ler que envolve três etapas distintas, em que a primeira é ler, a segunda é compreender e a terceira é interpretar. Essa visão do ato de ensinar a ler está relacionada à própria tradição histórica do ensino das línguas alfabéticas, em nosso caso, do português, em que a ênfase do ensino do ato de ler é colocada sobre a relação grafofônica, como o essencial a ser dominado, isolado do aspecto semântico, que seria uma consequência natural dessa relação, ou seja, havia uma ênfase no ensino do código, da relação letra-som, da vocalização num primeiro momento, para depois, e como consequência desse primeiro, atribuir sentido ao que foi vocalizado (ARENA, 20 I0). Assim, de acordo com esse ponto de vista, a primeira etapa, a de ler, seria a de ler para pronunciar, ler sem atribuir sentido; a segunda etapa seria a de compreender nas linhas e na superfície o que o autor do texto quis dizer de forma até literal; e a terceira etapa, a de interpretar, seria a capacidade do leitor de fazer inferências e relações com o conhecimento organizado em sua mente e com possível criticidade (ARENA, 20I0).

De acordo com os fundamentos teóricos deste artigo, portanto, ler é compreender, é produzir sentido, é uma prática social, histórica e cultural desde a pequena infância. Ler se entende sempre como uma atitude de compreensão, de estabelecer um diálogo com o texto e consigo mesmo, de construir e 
desconstruir o texto no interior do pensamento, de fazer perguntas ao texto (ARENA, 1992; CHARMEAUX, 1997; JOLIBERT, 1994) - conforme o leitor poderá encontrar nas páginas dirigidas à pesquisa de campo, notadamente às destinadas as situações de leitura com as crianças, sujeitos do experimento formativo.

que se enfatiza não é somente a natureza comunicativa da língua escrita, mas "o aspecto transformador das funções psíquicas superiores que permitem a inserção do homem diretamente nas relações humanas permeadas pelo gráfico, atualmente potencializado pelos processadores eletrônicos" (ARENA, 20 I0, p. 243).

Ler é a ação de produzir sentidos e essa função transformadora da língua exige que seu ensino seja compatível com essa exigência, em outras palavras, "obriga a didática da leitura a elaborar novas condutas metodológicas para atender a esse novo leitor e às novas funções redescobertas no ato de ler" (ARENA, 20 I0, p. 243). Com isso, considera-se que o ensino da língua, do ato de ler, foco deste artigo, requer do professor condutas metodológicas que possibilitem a produção de sentido, a aprendizagem e o desenvolvimento da criança.

Essas formas de se pensar o trabalho pedagógico para a sua inserção na cultura escrita, de colocála no fluxo dessa língua de modo que ela pense sobre a língua, estabeleça relações e perceba seu funcionamento de modo a utilizá-la conforme seus interesses e necessidades, é o desafio para os pesquisadores da área em questão. O professor ensina o ato de ler para que a criança possa criar leitura, porque a leitura acontece no momento em que o leitor a realiza; ela se dá na relação entre o leitor e o texto. A leitura não é um objeto, uma coisa. Ela existe no momento em que a realiza, "somente ganha existência quando o leitor a cria na relação entre o que ele é, o que sabe, e o que o texto criado pelo outro está a oferecer" (ARENA, 2010, p. 243). Dessa forma, o professor ensina "o modo como o leitor em formação deve agir sobre o texto para criar a leitura" (ARENA, 20 I 0, p. 243) e por essa razão, não se ensina a leitura, mas se ensina a criança a ler, como ato cultural, para criar a sua própria leitura, nos limites de sua potencialidade, na sua relação com os diferentes gêneros e suportes textuais que possibilitam a formação crescente e permanente de modos de pensar cada vez mais abstratos. (ARENA, 20 I0, p. 243).

Esses pressupostos fundamentam a tese de que as crianças aprendem a língua por meio dos gêneros discursivos, como aqui, por exemplo, por meio do gênero literário histórias em quadrinhos, quando o professor introduz o ensino dos gêneros na escola desde a Educação Infantil como instrumentos de humanização, como forma de apropriação da cultura humana. 


\section{SITUAÇÃO DE LEITURA DE HISTÓRIAS EM QUADRINHOS NA EDUCAÇÃO INFANTIL: SIGNIFICADO/SENTIDO NA LEITURA}

Para Bakhtin (1992), a palavra assume diferentes significados ao longo de sua história e depende diretamente do contexto em que é enunciada e dos sentidos atribuídos pelos indivíduos. $\bigcirc$ autor distingue na palavra o sentido e o significado. Para ele, o sentido é a soma de todos os eventos psicológicos que a palavra desperta em nossa consciência. O significado é mais estável e preciso. É dicionarizável. Pode-se dizer que é apenas uma das faces do sentido. Dessa maneira, os sentidos variam de acordo com a entonação expressiva determinada pela situação imediata e pelo contexto psicológico no qual ela estava sendo enunciada (BAKHTIN, 1992).

As concepções trazidas pela Teoria Histórico-Cultural se coadunam com as concepções de Bakhtin, sobre o significado e o sentido. Segundo essa teoria, os significados e os sentidos são conteúdos da consciência humana, sendo que os significados constituem a parte fundamental da consciência humana uma vez que neles "está representada a forma ideal - transformada e envolvida na matéria da linguagem - da existência do mundo material, de suas propriedades, vínculos e relações, revelados pela prática social conjunta" (LEONTIEV, 1978, p. 37, tradução nossa).

A apropriação dos significados pelo homem ocorre por meio da sua atividade e pela comunicação com os outros homens. Nesse sentido, os significados não existem sem as relações internas da atividade humana e sem a consciência (VYGOTSKY, 2000). De acordo com Vygotsky (2000), é na consciência que o significado se relaciona com o sentido - um outro elemento constituinte da consciência - e é na relação consciente com o sentido que os significados passam a ter seu traço psicológico, em outras palavras, a existirem como conceitos e generalizações. Disso decorre que o significado ao ser objetivado por meio da linguagem, por exemplo, vem carregado de sentido (LEONTIEV, 1979). E o sentido é objetivado, refletido nas relações com os motivos e com os objetivos da atividade humana (MARTINS, 2004).

A situação a seguir pode contribuir para corroborar a reflexão anterior e permitir perceber como ocorreu o processo de significação - significado/sentido - na leitura.

Figura I - Tirinha utilizada com crianças em situação de leitura.

Turma da Mônica Mauricio de Sousa
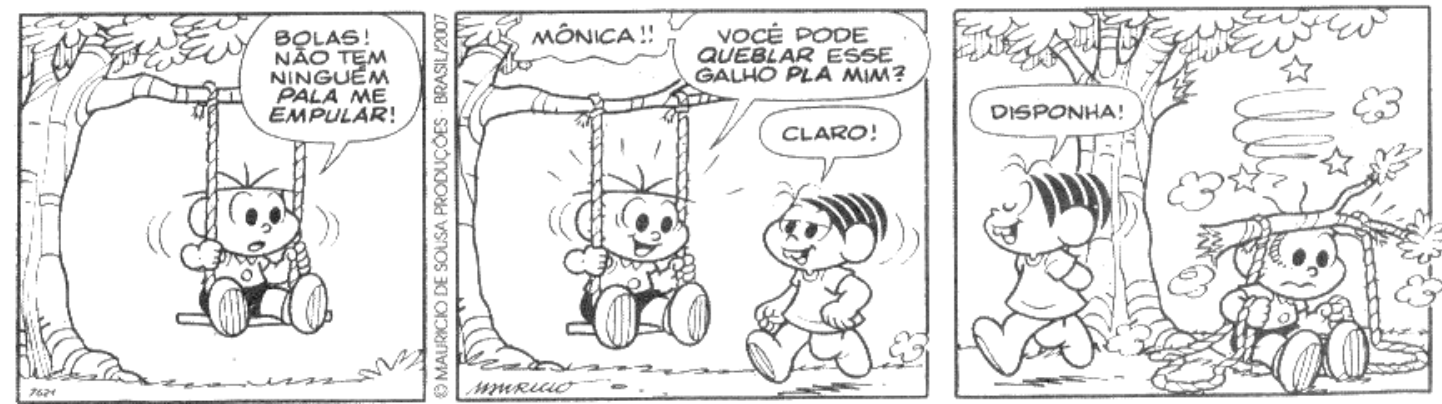

Fonte: SOUSA, Maurício. Turma da Mônica. O Estado de São Paulo. São Paulo, 12 de set. 2007. Humor, Caderno 2, p. D2. 
Após realizar na sala de aula a leitura de três tiras de histórias em quadrinhos de jornal, A7 solicita: Pro, lê uma do Cascão (tira). A professora pega outra tira da pasta que trazia no colo e indaga:

\section{P: Será que é do Cascão?}

Alunos: Cascão! Cascão! Cascão! Cascão! Cascão! (gritam todos juntos)

P: Vocês gostam do Cascão?

Alunos: Gostamos!

P: E por que vocês gostam dele?

A21: Porque ele não toma banho.

P: E vocês também não gostam é? (de tomar banho)

Alunos: Não!

A3: Eu gosto.

P: (Mostra a tira somente no primeiro quadrinho escondendo os demais com uma folha de papel sulfite) Não é do Cascão. É uma história do Cebolinha. E o A8 e o Al I vão me ajudar a contar essa história. O que vocês acham? (refere-se a dois alunos que se encontravam mais afastados do grupo)

A8 e Al I: (silenciaram)

P: O que o Cebolinha está fazendo?

Alunos: Balançando.

A3: Balançando no balanço.

A2 I: Sem ninguém.

$\mathrm{P}:$ O que ele está fazendo? (indaga novamente enquanto todos observam a tira)

A3: Ele está balançando sozinho.

P: Ele está tentando balançar sozinho. Ele está conseguindo?

Alunos: Não.

A3: Está parado!

P: Ele não está conseguindo balançar sozinho. Ele diz: "Bolas! Não tem ninguém pala me empular! Então a Mônica chegou, viu o Cebolinha lá no balanço na árvore e ele falou assim: "Mônica..." (a professora é interrompida por A3)

A3: Me balança?

$P$ : Será que foi isso que ele falou?

A3: É.

P: (A professora prossegue) Mônica, você pode queblar esse galho pla mim?

Claro! (respondeu a Mônica)

P: O que ele quis dizer com "quebrar esse galho?"

A3: Balançar.

P: Ajudá-lo a balançar. Vocês acham que a Mônica ajudou?

Alunas: Não!

O registro acima revela que as crianças atribuem significado à expressão chave da história, a expressão desencadeadora de toda a história que é "quebrar um galho". Contudo, ultrapassam somente o significado da expressão, compreendendo-a no contexto em que se dá a enunciação do personagem, fato esse que se revela pelas previsões e confirmações na leitura realizadas pelos alunos, e especificamente por A3.

A3: Ela quebrou o galho (faz o gesto como se estivesse quebrando o galho)

P: Ela quebrou o galho?

A3: E ele caiu do balanço (todos concordam com A3)

P: E como é que vocês sabem disso?

A7: Por causa do jeito dela (aponta para o quadrinho). Ela é nervosa...

P: (A professora retoma a história rapidamente) Olhem, o Cebolinha estava sozinho, não conseguia balançar. A Mônica chegou e ele falou: "Mônica, você pode queblar esse galho pla mim?".

A7: Ela quebrou e o galho caiu na cabeça do Cebolinha.

P: Ela quebrou o galho de que maneira? (a professora pergunta tentando resgatar o significado da expressão) 
A21: Assim ó (faz o gesto como se estivesse quebrando o galho de uma árvore)

A3: "TAC" (faz o barulho do galho sendo quebrado, a onomatopeia)

P: Ela quebrou o galho de verdade?

Alunos: Quebrou!

P: Mas foi isso que o Cebolinha pediu?

Alunos: Não.

A3: Ela entendeu isso.

P: Olhem só! (mostra o final, o desfecho da história da tira)

Há tiras em que é sugerida uma ideia inicial, mas é outro o sentido pretendido. Isso ocorre muito comumente nas piadas e tiras cômicas e é o que ocorre com a tira analisada acima com a expressão "quebrar um galho". No entanto, as crianças participantes da pesquisa aparentam revelar por suas falas e atitudes, que compreenderam o significado da expressão convencionalmente criado - "ajudar" - bem como o sentido que essa expressão tem no contexto da personagem Mônica que é caracterizada por ser forte e briguenta - "quebrar o galho da árvore".

A3: NÃO FALEI QUE ELA ENTENDEU ISSO TIA? (refere-se à professora)

P: Realmente. "Disponha", ela falou. "Disponha". Ela (a Mônica) entendeu errado, porque o Cebolinha havia pedido só para ela ajudar ele a balançar um pouco. Quando a gente fala "Ah, você pode quebrar esse galho pra mim?" é o mesmo que dizer: "Você pode me ajudar?", "Você pode me dar uma mãozinha?". Só que a Mônica entendeu tudo exatamente do jeito que ele falou. Quebrar um galho para ela era quebrar um galho MESMO, um galho da árvore. Coitado do Cebolinha, o galho caiu em cima da cabeça dele! Nossa, e o que está saindo em cima da cabeça do Cebolinha?

Alunos: Estrelinhas

A3: Estrelinhas... porque doeu a cabeça dele. E ele também está vendo estrelinhas porque a gente vê estrelinhas quando alguém bate.

P: Porque quando alguém bate em algum lugar e dói muito, a gente parece estar vendo estrelinhas, não é? De dor.

A3: É... e quando dói o dente da minha mãe ela fala que ela está vendo estrelinhas... (Situação filmada no dia 29//0/07).

Bakhtin (1992) denomina de mobilidade específica da forma linguística a ideia de que a palavra pode conciliar em si muitas significações diferentes. A esse caráter móvel da palavra, Bakhtin (1992) chama de polissemia, uma vez que ela pode adquirir significações relativas ao contexto em que é usada e por quem é utilizada. Nesse caso, as crianças percebem o significado da expressão "Quebrar um galho" devido ao contexto em que é empregada - no gênero discursivo histórias em quadrinhos que é caracterizada por apresentar o humor, o improvável - e por quem é utilizada - as personagens que possuem traços físicos e psicológicos marcantes. Segundo Bakhtin (1992, p. 106),

o sentido da palavra é totalmente determinado por seu contexto. De fato, há tantas significações possíveis quantos contextos possíveis. No entanto, nem por isso a palavra deixa de ser uma. Ela não se desagrega em tantas palavras quantos forem os contextos nos quais ela pode se inserir. Evidentemente, essa unicidade da palavra não é somente assegurada pela unicidade de sua composição fonética; há também uma unicidade inerente a todas as suas significações. Como conciliar a polissemia da palavra com a unicidade?

Para responder a essa questão, Bakhtin diferencia tema de significação. Para ele, 
o tema é um sistema de signos dinâmico e complexo, que procura adaptar-se adequadamente às condições de um dado momento da evolução. $\bigcirc$ tema é uma reação da consciência em devir ao ser em devir. A significação é um aparato técnico para a realização do tema. (BAKHTIN, 1992, p. 129, grifos do autor).

Desse modo, o tema é um termo amplo, é a expressão de um contexto interno construído com base nas relações históricas concretas em que o indivíduo vive. Nesse contexto ele pode pronunciar um enunciado com significação correspondente ao interior desse contexto que é o tema. Segundo Bakhtin (1992), não é possível haver tema sem significação e nem significação sem tema. Por tal razão, é que o devir pode ser entendido como movimento, mudança, em que Bakhtin ( 1992) acredita na mobilidade da significação devido ao caráter polissêmico da palavra em seu contexto histórico e cultural.

É possível depreender que ao produzirem diálogo, as crianças se apropriam dos conceitos criados socialmente. Nesse sentido, as ideias de Vygotsky estão em consonância com as de Bakhtin e nessa direção é relevante assinalar que a leitura possibilita

esse enriquecimento do significado da palavra com o sentido [...] A palavra está inserida em um contexto do qual toma seu conteúdo intelectual e afetivo, se impregna deste conteúdo e passa a significar mais e menos do que significa isoladamente e fora do contexto (textual): mais porque se amplia seu repertório de significados, adquirindo novas áreas de conteúdo; menos, porque o contexto em questão limita e concretiza seu significado abstrato. O sentido da palavra [...] é um fenômeno complexo e móvel que, em certa medida, muda constantemente de umas consciências a outras e de umas situações a outras para a mesma consciência. [...] Em definitivo, o sentido das palavras depende conjuntamente da interpretação do mundo de cada um e da estrutura interna da personalidade. (VYGOTSKY, 1993, p. 333-334).

Se ao produzirem diálogo as crianças se apropriam dos conceitos criados socialmente, nesse processo de significar todo o seu entorno, em movimento constante, concordamos que criar condições apara a imersão das crianças na cultura escrita é modificar a relação com a linguagem e com o mundo a sua volta (BERNARDIN, 2003). Na medida em que a criança vivencia a experiência dos objetos da cultura escrita, os modos como os seus gêneros são organizados, é que encontrará sentido nela. (BRITTO, 2005, p. 17), como ocorreu nos episódios acima descritos. A condição de participação na cultura escrita está intimamente relacionada tanto a discursos que se elaboram em diferentes instituições e em práticas sociais orais e escritas, quanto a muitos objetos, procedimentos, atitudes, como formas sociais de expressão, entre elas a expressão em língua escrita (GOULART, 2006, p. 450). Assim, é possível pensar que é na Educação Infantil que as crianças devem iniciar esse processo de inserção e participação na cultura escrita, e é na escola da pequena infância que se deve pensar nos modos de se promover vivências para que essa inserção e participação ocorram de forma necessária e adequada. $\bigcirc$ processo de apropriação e o de objetivação da língua escrita são, na essência, um único processo: o de internalização da língua em seu funcionamento, como conjunto sígnico de interação entre as pessoas. Nessa perspectiva, não se dicotomiza alfabetização e letramento como dois processos separados, mas como um processo discursivo interativo para a humanização das crianças. 
Ao se tratar da formação leitora de textos na Educação Infantil, vale ressaltar que não estamos a defender uma antecipação da alfabetização. A antecipação da escolarização, por exemplo, e acrescentemos, da alfabetização, é sustentada pela ideia de quanto mais cedo a criança for introduzida de forma sistemática nas práticas da escrita, quanto mais cedo assumir o estatuto de aluno, maiores serão suas possibilidades de sucesso na escola, na vida e no progresso tecnológico do país. Isso decorre da pressão dos pais, mas principalmente da formação dos professores que trabalham com a Educação Infantil (MELLO, 2005).

Para nós, de acordo com Vigotskii ( 1988 , p. I l0), "aprendizagem e desenvolvimento não entram em contato pela primeira vez na idade escolar, mas estão ligados entre si desde os primeiros dias de vida da criança”. A aceleração da escolarização (ZAPHORÓZETS, 1987; MELLO, 1999) e a preocupação em alfabetizar as crianças na Educação Infantil - com ênfase no domínio do código linguístico, sem fazer o uso social da leitura e da escrita para o cotidiano - faz perpetuar procedimentos de educação tecnicista (BRITTO, 2005), abrevia a infância e influencia todo o desenvolvimento da inteligência e da personalidade da criança (MUKHINA, 1996; MELLO, 1999). Dessa maneira, o ensino e a aprendizagem da leitura e da escrita não a envolvem, porque são destituídos de sentido para ela e, na maioria das vezes, não se tornam atividades no sentido defendido por Leontiev (1988).

Na situação anteriormente descrita, percebe-se o esforço da mediadora em criar situações promotoras do desenvolvimento infantil, por isso mesmo carregadas de significado/sentido, de tal forma que as crianças também compreendem os signos não verbais como aqueles apresentados nas metáforas visuais, no caso, as estrelinhas que estão acima da cabeça do personagem Cebolinha depois que o galho, quebrado pela personagem Mônica, cai em cima dele.

As metáforas visuais atuam no sentido de expressar sentimentos enfatizando, muitas vezes, o signo verbal. Elas se constituem "em signos ou convenções gráficas que têm relação direta ou indireta com expressões do senso comum" (VERGUEIRO, 2006, p. 54). Assim, as metáforas visuais - signos não verbais -, aliados aos signos verbais, contribuem para a compreensão do texto. Esses apontamentos podem ser observados na fala de A3 quando explica a razão do aparecimento das estrelas na cabeça do Cebolinha significado - e quando conclui remetendo essa situação a algo pessoal, vivenciado como a situação de dor de dente da sua mãe - sentido.

Mediante a análise dos dados apresentados, reiteramos a fundamental importância do diálogo na apropriação do processo de atribuir significado/sentido na leitura das crianças participantes desse trabalho. O diálogo promove e permite que a compreensão ocorra, uma vez que as crianças ouvem suas vozes expressas em opiniões e impressões, ouvem a voz do texto e da professora e refratam ou refutam de acordo com os significados e sentidos que atribuem à leitura das histórias em quadrinhos. Por meio da 
análise dos dados ora apresentados pode-se dizer que o diálogo impulsiona o processo de significação na leitura.

Compreender a essencialidade da imersão da criança pequena no mundo da cultura escrita, é crucial para o entendimento da organização de um trabalho pedagógico desde a Educação Infantil com a língua viva, dirigido aos processos de apropriação/objetivação da leitura pela criança pequena. Não se trata somente de oferecer grande quantidade de informações em distintos gêneros discursivos ofertados, porque isso não garante a apropriação de informações, por vezes superficiais, neles contidas. $\bigcirc$ que se enfatiza são as relações dialógicas de alteridade desde a infância pequena, trocas com signos verbais e não verbais, por exemplo, do gênero histórias em quadrinhos, que as crianças vão estabelecer e, ainda, a maneira pela qual estas relações serão mediadas pelo professor ou por outros.

\section{PALAVRAS FINAIS}

Como palavras finais para o artigo, em tela, precisamos fazer algumas retomadas. Ao compreendermos que o ensino da língua se dá por meio de enunciados, de gêneros, de situações dialógicas, é possível entender-se que o ensino da leitura desde a Educação Infantil, pode ocorrer de forma a provocar as crianças a pensar sobre a escrita, a estabelecer relações intensas com ela, a dialogar em situações reais de comunicação, em outras palavras, em situações únicas de comunicação em que a existência do outro é uma condição.

Precisamos retomar que o processo de ensino e de aprendizagem do ato de ler, mediante vívidas práticas de leitura, é um diálogo que se estabelece entre a criança e a cultura escrita. Precisamos reiterar de que ela não se apropriará do ato de ler somente porque pais e professores desejam, ou porque os professores dão tarefas de reprodução repetitiva de grafar as letras e de oralizá-las, mas porque poderão se apropriar do ato de ler em genuínas situações de leitura, porque poderão se apropriar do ato de ler somente e quando fizerem sentido para elas, quando conviverem com esses atos de forma dialógica e dinâmica, quando o resultado corresponder a uma necessidade criada segundo os preceitos de Leontiev (1988). Quando nesses processos de ensino, aprendizagem e de desenvolvimento, entender-se que o sujeito leitor em formação desde pequeno aprende historicamente, num dado contexto cultural, dentro das condições de vida e de educação de leitura adequadas e dirigidas a este fim; de que aprende a criança nas relações com o outro dialógica e dialeticamente uma vez que são capazes de aprender a ter uma atitude responsiva, de refletir, refratar ou refutar aquilo que veem, ouvem, percebem, pensam, e essa atitude diante do conhecimento, da leitura, contribuirá para que elas se constituam como leitoras de forma interativa (BAKHTIN, 2003). 
Ademais, como vimos, aprendizagem da linguagem escrita provoca um salto qualitativo no desenvolvimento da inteligência da criança que aprende a ler, uma vez que essa aprendizagem amplia e desenvolve os mecanismos cerebrais usados para pensar, porque a escrita é um instrumento cultural complexo (VYGOTISKI, 1995).

De todo o exposto, colocar para a criança o signo linguístico e a enunciação linguística plenos de significação, contextualizados e marcados pela vivência, pode restituir ao ensino e à aprendizagem na pequena infância a própria língua materna viva (e, aqui, o ato de ler vivo) antes destruída fragmentada e reduzida à sinalidade, na perspectiva bakhtiniana, pelos "não - textos" cartilhescos (ARENA, 1992), ou seja, a língua em sua totalidade concreta, em seu uso real, em sua propriedade de ser dialógica por natureza.

Por fim, consideramos que a fundamentação teórica calcada em Bakhtin e seu círculo, em diálogo com Vygotsky e estudiosos da Teoria Histórico-Cultural e contemporâneos estudiosos da leitura, assinala a possibilidade de se rever as propostas de ensino e de aprendizagem do ato de ler com as crianças pequenas em busca de um ensino, que privilegie a interlocução e a criança como sujeito desse processo, como protagonista que constrói e é construída pela sua história.

\section{REFERÊNCIAS}

ARENA, D. B. Bakthin e Alfabetização. Educação, Santa Maria - RS, v. 17, p. 7I - 89, 1992.

ARENA, D. B. O ensino da ação de ler e suas contradições. Ensino Em-Revista, Uberlândia, v. 17, n. I, p. 237-247, jan/jun. 2010.

ARIÉS, P. A História Social da Criança e da Família. Rio de Janeiro - RJ: Ed. Guanabara, 1978.

BAKHTIN, M. Marxismo e filosofia da linguagem. 5. ed. Tradução Michel Lahud e Yara Frateschi Vieira. São Paulo: Hucitec, 1992.

BAKHTIN, M. Estética da criação verbal. São Paulo: Martins Fontes, 2003.

BERNARDIN, J. As crianças e a cultura escrita. Porto Alegre: Artmed, 2003.

BISSOLI, M. F. Educação e desenvolvimento da personalidade da criança: contribuições da teoria histórico-cultural. 2005. [28I] f. Tese (Doutorado em Educação) - Faculdade de Filosofia e Ciências, Universidade Estadual Paulista, Marília, 2005.

BRITTO, L. P. L. Letramento e Alfabetização: Implicações para a Educação Infantil. In: FARIA, A. L. G.; MELLO, S. A. (org.). O mundo da escrita no universo da pequena infância. Campinas, SP: Autores Associados, 2005. (Coleção Polêmicas do nosso tempo, 93). p. 5 -21.

CHARMEUX, E. Aprender a ler: vencendo o fracasso. Tradução Maria José do Amaral Ferreira. 4. ed. São Paulo: Cortez, 1997.

FOUCAMBERT, J. A leitura em questão. Porto Alegre: Artes Médicas, 1994. 
GOULART, C. M. A. Letramento e modos de ser letrado: discutindo a base teórico-metodológica de um estudo. Revista Brasileira de Educação. v. II, n. 33, set/dez. 2006.

JOLIBERT, J. Formando crianças leitoras. Tradução Walquíria M. F. Settineri e Bruno Charles Magne. Porto Alegre: Artes Médicas, v. II, 1994.

KOSIK, K. Dialética do concreto. Trad. Célia Neves e Alberico Toríbio. 2. ed. Rio de Janeiro: Paz e Terra, 1976.

LEONTIEV, A. N. O desenvolvimento do psiquismo. Lisboa: Livros Horizonte, 1978.

LEONTIEV, A. N. Uma contribuição para a Teoria do Desenvolvimento da Psique Infantil. In: VIGOTSKII, L. S.; LURIA, A. R.; LEONTIEV, A. N. Linguagem, Desenvolvimento e Aprendizagem. SP: Ícone/EDUSP, 1988. p. $59-83$.

MARTINS FILHO, A. J. Jeitos de ser criança: balanço de uma década de pesquisas com crianças. In: MARTINS FILHO, A. J.; PRADO, P. D. (org.). Das pesquisas com crianças à complexidade da infância. Campinas, SP: Autores Associados, 2011.

MARTINS FILHO, A. J.; BARBOSA, M. C. S. Metodologias de pesquisas com e sobre crianças. In: Simposio Internacional Encuentro etnográficos com niñ@s adolescentes em contextos educativos. Universidade Federal do Rio Grande do Sul. Disponível em: http://www.ufrgs.br/faced/pesquisa/gein/artigos/METODOLOGIAS\%20DE\%20PESQUISAS\%20COM \%20E\%20SOBRE\%20CRIAN\%C3\%87AS.pdf. Acesso em: 4 jan. 201 I .

MARTINS, L. M. A natureza histórico-social da personalidade. Caderno Cedes, Campinas, v. 24, n. 62, p. 82 - 99, abril, 2004. Disponível em: http://www.cedes.unicamp.br. Acesso em: 16 fev. 2007.

MARX, K. Manuscritos econômico-filosóficos e outros textos escolhidos. São Paulo: Abril Cultural, 1974. (Os Pensadores).

MELLO, S. A. Algumas Implicações Pedagógicas da Escola de Vygotsky para a Educação Infantil. ProPosições, Campinas, v. 10, n. I, p. 16 - 27, 1999.

MELLO, S. A. O processo de aquisição da escrita na Educação Infantil - Contribuições de Vygotsky. In: FARIA, A. L. G; MELLO, S. A. (org.). Linguagens Infantis - Outras formas de Leitura. Campinas, SP: Autores Associados, 2005. (Coleção Polêmicas do nosso tempo, 9l). p. 23 - 40.

MELLO, S. A. Infância e humanização: algumas considerações na perspectiva da teoria histórico-cultural. In: Perspectiva: Revista do Centro de Educação e Ciências Humanas. Florianópolis, v. 25, n. I , 83 - 104 , jan/jun. 2007. Disponível em: http://www.perspectiva.ufsc.br. Acessado em: 20 fev. 2008.

MOYA, Álvaro de. História da história em quadrinhos. São Paulo: Brasiliense, 1993.

MUKHINA, V. Leis fundamentais do desenvolvimento psíquico. In: Psicologia da Idade Pré-escolar. Tradução Claudia Berliner. São Paulo: Martins Fontes, 1996. p. 35 - 70.

QVORTRUP, J. A infância na Europa: novo campo de pesquisa social. Centro de documentação e informação sobre a criança. Instituto de Estudos da Criança, Universidade do Minho. Tradução de Helena Antunes, 1999. 
SARMENTO, M. J.; PINTO, M. As crianças e a infância: definindo conceitos, delimitando o campo. In: SARMENTO, M. J.; PINTO, M. As crianças: contextos e identidades. Braga, Portugal: Universidade do Minho. Centro de Estudos da Criança. Ed. Bezerra, 1997.

SILVA, G. F. O leitor e o re-criador de gêneros discursivos na educação infantil. 20 13. [3 |6] f. Tese (Doutorado em Educação). Faculdade de Filosofia e Ciências, Universidade Estadual Paulista, Marília, 2013.

VERGUEIRO, V. Como usar as histórias em quadrinhos na sala de aula. 3. ed. São Paulo: Contexto, 2006. (Coleção Como usar na sala de aula).

VIGOTSKII, L. S. Aprendizagem e desenvolvimento intelectual na idade pré-escolar. In: VIGOTSKII, L. S.; LURIA, A. R.; LEONTIEV, A. N. Linguagem, Desenvolvimento e Aprendizagem. SP: Ícone/EDUSP, 1988. p. $103-117$.

VYGOTSKY, L. S. Obras Escogidas II. Madrid: Visor Distribuiciones, S.A. 1993.

VYGOTSKI, L. S. Obras Escogidas III. Madrid: Visor Distribuiciones, S.A. 1995.

VYGOTSKY, L. S. A construção do pensamento e da linguagem. São Paulo: Martins Fontes, 2000.

ZAPORÓZHETS, A. Importancia de los períodos iniciales de la vida en la formación de la personalidad infantil. In: DAVIDOV, V.; SHUARE, M. (org.). La Psicología Evolutiva y Pedagógica em la URSS (Antologia). Moscou: Editorial Progreso. 1987. p. 228 - 249.

\section{COMO CITAR ESSE ARTIGO}

\section{Associação Brasileira de Normas Técnicas (ABNT) - NBR 6023:2018}

SILVA, Greice Ferreira da; GIROTTO, Cyntia Graziella Guizelim Simões; BALÇA, Ângela Maria Franco Martins Coelho de Paiva. Leitura e leitores na Educação Infantil: as histórias em quadrinhos e a apropriação do ato de ler. Debates em Educação, Maceió, v. 12, p. I |6- I3 I, dez. 2020. ISSN 2 I756600. Disponível em: https://www.seer.ufal.br/index.php/debateseducacao/article/view/9931. Acesso em: dd mmm. aaaa.

\section{American Psychological Association (APA)}

Silva, G., Girotto, C., \& Balça, Â. (2020). Leitura e leitores na Educação Infantil: as histórias em quadrinhos e a apropriação do ato de ler. Debates em Educação, 12(Esp), ||6-|3|. doi: https://doi.org/10.28998/2175-6600.2020v I2nEspp | |6-131 